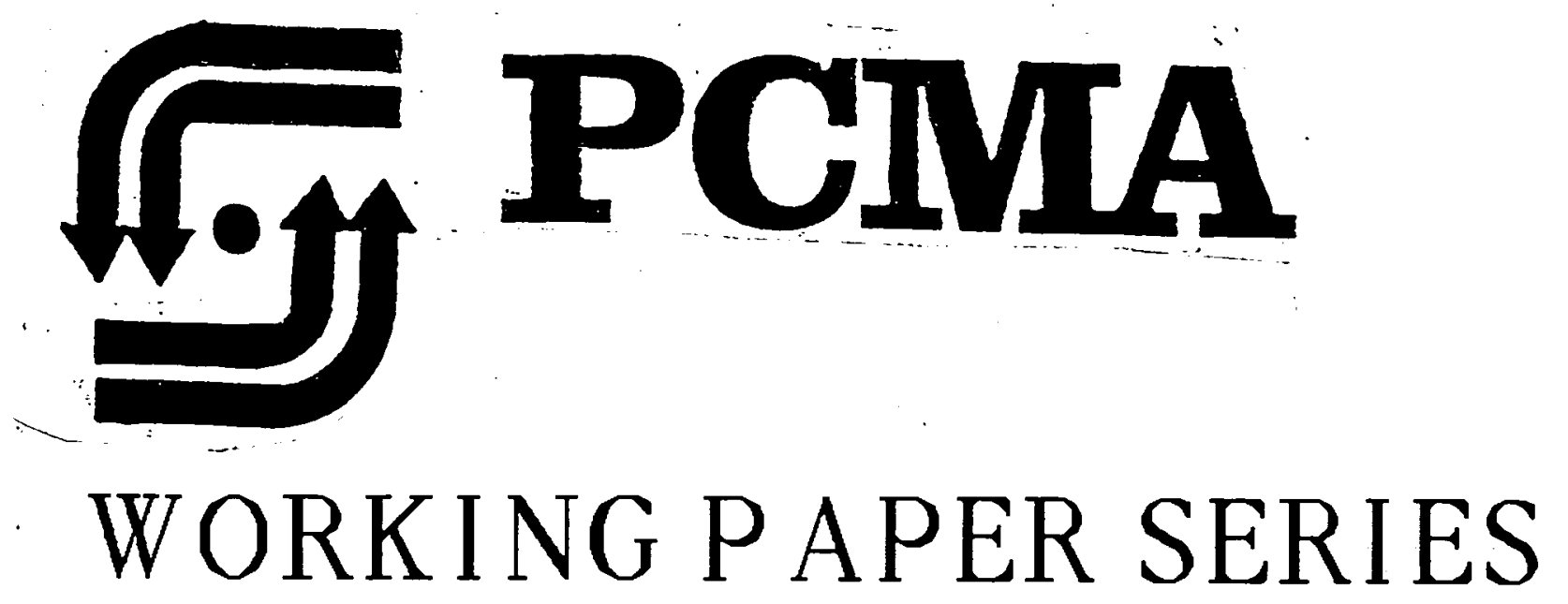

Empowerment as a Multi-Level Construct:

Perceived Control at the Individual, Organizational and Community Levels

By: Amy J. Schulz, Barbara A. Israel Marc A. Zimmerman and Barry Checkoway

\author{
PCMA WORKING \\ $P A P E R * 40$ \\ CRSO WORKING \\ PAPER 4095 \\ March 1993
}

The Program on Conflict Management Alternatives at The University of Michigan 


\section{Empowerment as a Multi-Level Construct: Perceived Control at the Individual, Organizational and Community Levels}

\author{
Amy J. Schulz, M.P.H. \\ Research Associate \\ Department of Sociology \\ Marc A. Zimmerman, Ph.D. \\ Assistant Professor \\ Health Behavior and \\ Health Education \\ School of Public Health
}

Barbara A. Israel, Dr. P.H. Associate Professor Health Behavior and Health Education School of Public Health Barry N. Checkoway, Ph.D. Professor School of Social Work

The University of Michigan

Ann Arbor, Michigan 48109

The authors wish to express their appreciation to Steven Rosenstone who was the Principal Investigator for the Detroit Area Study from which the data for this study was drawn. We also thank Elizabeth Chapleski, Betsy Moles, the studentś who participated in the Detroit Area Study, and the Detroit area residents who participated in the interviews. All correspondence should be sent to Amy Schulz, Department of Sociology, University of Michigan, Ann Arbor, Michigan, 48109. 


\begin{abstract}
There has been increasing interest in the development of a conceptual framework and operationalization of empowerment that explores the relationships among different levels of analysis: individual, organizational and community. In this article we discuss a multi-level conceptualization of empowerment, examine empirical support for linking the different levels of analysis, and describe a measurement instrument developed to assess perceived control at the individual, organizational and community levels. We then present results of a series of multiple regression analyses which examine correlates of perceived control, a partial measure of empowerment, at these three levels. Participation in organizations which attempt to influence public policy, taking an active or leadership role in a voluntary organization, and belief that taking action is an effective means to influence community decisions are important predictors of perceived control at the organizational and community levels. Limitations of the study and implications for practice are discussed.
\end{abstract}




\section{Introduction}

An empowerment perspective is grounded in the belief that increasing power and control over individual and community events is an important means to improve the life situations of powerless individuals and groups. The concept of empowerment has been explored in a variety of disciplines, including adult education (Freire, 1970), social work (Gutierrez, 1988a, 1988b, 1989), AfricanAmerican studies (Solomon, 1970; Haniff, 1989), feminist studies (Collins, 1990; Bookman and Morgen, 1988), psychology (Bandura, 1982; Maier and Seligman, 1976; Zimmerman and Rappaport, 1988; Zimmerman, 1990a, 1990b; Kieffer, 1984), and health education (Israel, Checkoway, Schulz and Zimmerman, 1992; Wallerstein, 1992). Different conceptualizations of empowerment have ranged from empowerment at the individual level as an increased sense of control or power over personal life events, to political empowerment with its emphasis on increased control over the distribution of social and economic resources.

Increasingly, there has been interest in the development of a conceptual framework which explores the relationships among different levels of empowerment: how participation in voluntary organizations or community concerns can enhance individual empowerment and vice versa (see for example, Gutierrez, 1988a, 1988b). In addition, there has been interest in the development of accurate measures of the changes which can occur at these multiple levels as individuals work within organizations and communities to create social change (Wallerstein, 1992). The work described in the following pages contributes to this discussion. A conceptual model of empowerment which incorporates individual, organizational and community levels of analysis is outlined. Next we discuss the development of a series of scales which focus on perceptions of individual, organizational and community control. Finally, we explore the relationship of these scales to behavioral and perceptual measures related to empowerment. The two primary 
research questions that we address are: 1) what is the relationship of organizational membership to perceived control at the individual and community levels of analysis?; and 2) what are the predictors or correlates of perceived control at the different levels of analysis among individuals who are members of at least one voluntary organization?

\section{Conceptual Framework and Empirical Evidence: Empowerment as a Multilevel Construct}

...empowerment is... a social action process that promotes participation of people, organizations and communities towards the goals of increased individual and community control, political efficacy, improved quality of community life, and social justice (Wallerstein, 1992, p. 198).

The conceptual framework which forms the basis for this study focuses on empowerment and empowering processes at the individual, organizational and community levels (Schulz and Israel, 1990). The framework examines empowerment at the three levels of analysis, as well as the linkages and interactions between individual and collective or political power (for a more in-depth examination of this conceptual framework, see Israel, Checkoway, Schulz and Zimmerman, in press).

Individual empowerment and psychological empowerment

Perceived control at the individual level has been explored in research on self-efficacy and learned helplessness (Bandura, 1982; Maier and Seligman, 1976). Bandura's conception of self-efficacy involves beliefs about one's ability to "produce and regulate events in life" (Bandura, 1982, p. 122). An explicit connection is not made between individual perceptions of power and objective social or economic conditions which may facilitate or circumscribe individual control over life events. Learned helplessness focuses on the consequences of a lack of control over life events, linking apathy and passive behavior to repeated failed attempts to exert control. 
The concept of psychological empowerment moves beyond a focus on perceptions of control (the intrapsychic component) to include behavioral and contextual components. Perceptions of influence or efficacy are explicitly linked with participation in organizational or community change efforts and the concurrent development of analytical and practical skills (Zimmerman, 1990a, 1990b; Zimmerman and Rappaport, 1988; Florin and Wandersman, 1990). Although the focus remains at the individual level, the analysis places the individual firmly within a social context:

We can say that individuals are 'empowered' as they become able to participate in the dynamics of social relations with a personal sense of potency, critical political awareness, and practical strategic skills. Empowerment then is the process of developing participatory competence. (Community activist, cited in Gerschick, Israel and Checkoway, 1990, p. 7)

Other conceptualizations of empowerment at the individual level have emphasized the development of personal power or strength, the ability to take action, or improved interaction skills (Solomon, 1976; Stensrud and Stensrud, 1982; Pinderhughes, 1985). Linkages between empowerment at the individual level and at organizational and community levels are made explicit by linking development of personal power and ability to act to opportunities for social support and development of interpersonal and social or political skills (Kieffer, 1984; Russell and Sarri, 1984; Withorn, 1980).

\section{Organizational empowerment}

The concept of organizational empowerment draws heavily on democratic management theory, and incorporates the dual themes of empowering and empowered organizations (Crowfoot, 1981; Gibson, Ivanavich and Donnelly, 1973; Gerschick, Israel and Checkoway, 1990; Zimmerman, 1991). Empowering organizations are those which provide opportunities for individual growth and access to decision making processes. Empowering organizations are cooperatively controlled by their members and work toward goals defined by those members, 
within the parameters of external opportunities and constraints (Crowfoot, 1981). Individuals may develop skills and a sense of personal effectiveness through participation and leadership opportunities within the organization. Empowered organizations are those with control and influence over their environments and the ability to affect the distribution of social and economic resources. The conception of organizations as both empowered and empowering helps to link the individual and the collective levels of empowerment. Individuals work within cooperatively managed organizations and become empowered through the development of skills and the opportunity to participate in processes of decision making and goal setting with other members of the group. In turn, these individuals empower the organization to effectively work toward organizational goals within the context of the physical, social, economic and political environment in which they exist.

\section{Community empowerment}

Some concepts of collective empowerment have focused on political empowerment, emphasizing political power and influence over resource allocation while minimizing individual action and transformation as aspects of social change processes (Alinsky, 1972). In contrast, our conceptualization considers the community to be made up of the individuals and organizations within that community. Individuals experience personal change through work to create change within the community or through influence on public policies. Organizations affect both individuals working within them and the distribution of resources in the larger community. Communities in turn affect both individuals and organizations through shaping access to social, political and economic resources. Thus, empowerment at the community level is inextricably linked with empowerment at the individual and organizational levels.

An empowered community is a community within which individuals and organizations apply their skills and resources in collective efforts that lead to community competence. Through such participation and control, the 
community is able to meet the needs of its individuals and organizations. (Gerschick, Israel and Checkoway, 1990, p. 7)

\section{Conceptual linkages among empowerment levels}

This multilevel concept of empowerment links the individual, organizational and community levels of empowerment. It suggests interactions among the multiple levels and suggests that change at one level will be linked to changes at other levels. According to this model, as action at the organizational or community level results in effective influence, individuals who are engaged in the process perceive that they have greater control, and personal empowerment is enhanced. Voluntary organizations play an important intermediary role between the individual and the community, providing the opportunity for individuals to come together with others with similar goals or experiences, and opportunities and structures to support individual efforts and skill building. Individual efforts in turn enable the organization to influence the allocation of social resources within the larger community. Therefore, elements of this definition of empowerment include a sense of personal control or efficacy, the availability of resources (including personal skills and access to organizational, social and economic resources) to influence organizational and community issues, a commitment to enhance the existing strengths of individuals, organizations and communities, and "a belief that power is not a scarce commodity, but one which can be generated in the process of empowerment" (Gutierrez, 1988a, p.4). Perceived influence at the organizational and community levels both shapes and is shaped by perceptions of individual control.

This definition of empowerment builds on the work of Paulo Freire (1970, 1973) in adult literacy and community development. Freire developed the concept of critical consciousness as a tool for linking the three conceptual levels of empowerment described above. Critical consciousness involves identification with a 
group and a sense of shared fate with that group, a critical analysis of social and economic systems, and a sense of self and collective efficacy to work toward greater equity in those systems. Freire's model places the individual within the context of a group or community as they develop the personal skills and social resources to create change. A combination of action and reflection provide the basis for the empowerment of individuals, organizations and communities.

\section{Empirical evidence for a multilevel construction of empowerment}

Gutierrez (1989) has explored the linkages between a sense of collective consciousness and group activity. In a study of Latino and Latina college students, she found that those who came together to discuss common issues and problems were more likely to develop a sense of collective identity and of shared fate with other Latinos than were students who did not have opportunities for such discussion. This work supports the linkage between the group and individual levels of analysis by suggesting that the process of coming together as a group can facilitate aspects of critical consciousness.

Chesler and Chesney (1988) have explored the effects of participation in self help groups on the attitudes and behaviors of disabled or chronically ill individuals. Their findings suggest that participation in self help groups promotes the development of social support networks, sharing information, and the development of coping and problem solving skills. These findings suggest that individuals involved in groups may be more likely to report a sense of control over life events than individuals who are not involved in groups.

The dynamic relationship between individual and political empowerment has been explored by Kieffer (1984) in an analysis of fifteen community activists. Based on this analysis, he has suggested two critical processes which contribute to empowerment. The first is a process of individual conflict and resolution leading to a sense of competence: as individuals are challenged (or challenge themselves) and 
meet these challenges, they develop an increased sense of personal competence and confidence. The second aspect of empowerment is praxis, an ongoing process of action and reflection through which individuals continually learn and confirm their commitment to change. Kieffer suggests that perceptions of individual competency are linked with engagement in community efforts to influence political or social concerns. Actions taken to influence community issues and participation in organizations which attempt to influence or shape public policy are thus important aspects of perceptions of control.

Research in the health field has explored the links between powerlessness, social participation, and indicators of mental and physical well being. Increased control and influence over life events have been linked with improved mental and physical health indicators (Schultz, 1980), while indicators of powerlessness such as poverty, lack of control over life events, and the presence of chronic life stressors have been linked with feelings of helplessness and hopelessness as well as higher risk of morbidity and mortality (Israel, Schurman and House, 1989; Kasl and Cooper, 1987; Syme, 1986). Occupational stress research has linked participation

and influence at the organizational level with increased feelings of personal efficacy, control, job satisfaction, and physical and mental health (Israel, Schurman and House, 1989; Israel, House, Schurman, Heaney and Mero, 1989). These findings suggest that efforts to influence life events, whether as an individual or through organizational activities, is related to a sense of control. Perceived control is, in turn, linked to physical and mental health outcomes.

\section{A conceptual model for the correlates of empowerment}

Based on the framework and empirical evidence described above, the conceptual model used to test the research questions examined in this study is presented in Figure 1. The model begins with a list of demographic variables which serve as proxies for social position or power: race, age, gender, income and 
education (Block 1). We hypothesize that in the United States education, income and age will be positively correlated with perceived control. In addition, we anticipate that white race and male gender will be positively associated with measures of perceived control.

Once demographic characteristics are controlled for, attitudes or beliefs about the effectiveness of taking action to influence personal, organizational or community events are expected to be positively correlated with perceived control (Block 2).

The model then moves to the level of action or behavior (Block 3). It is expected that individuals who report having taken action to influence community events within the past year will report higher levels of perceived control. Next we consider the extent to which individuals are involved in organizations which attempt to influence public policy (Block 4). The conceptual framework suggests that individuals involved with organizations which attempt to influence public policy will report higher levels of perceived control at each of the three conceptual levels. It is anticipated that this effect will be influenced by the extent to which individuals are involved in organizational activities and leadership roles (Block 5), with individuals who report more extensive engagement in organizational activities and leadership expected to report higher levels of perceived control at each of the three levels (Block 6).

Figure 1 Here

Interactions among the various levels are likely. For example, level of activity and leadership roles in organizations may lead to the development or enhancement of skills, contributing in turn to changes in attitudes about the efficacy of taking action. The analysis described here focuses on the linear linkages while recognizing the importance of interactions and feedback loops among the various components. 
The research reported here examines selected components of this conceptual model. Individual perceptions of control at the individual, organizational and community levels are assessed, along with correlates of these perceptions.

\section{Methods: Measurement of Perceived Control at Multiple Levels Study population and procedure}

The data used for these analyses were collected as part of the Detroit Area Study (DAS), a large random-sample survey conducted annually by the Sociology Department at the University of Michigan. The development of the survey questionnaire, the collection of data through in-person interviews, and data analysis are conducted by graduate students as part of their training in survey research.

The 1989 DAS examined the social, economic and political profile of the city of Detroit and two surrounding counties; community member's views of the most important problems facing these communities; and the nature and extent of public involvement in community problem solving. Face-to-face interviews were conducted between April and August of 1989 with 916 randomly selected adults from forty-seven communities in the greater Detroit area. The average interview time was one hour. The study used a multi-stage area probability sample of housing units in the tri-county area, proportional to estimated sample size (466 residents), and over-sampled residents in the city of Detroit (450 residents).

\section{Measurement of major variables}

Perceived control at three levels of analysis. Twelve questions were developed to assess individual perceptions of control or influence at the three levels of analysis individual, organizational and community. The items were pretested and modified prior to the field season. Our goal was to develop indices measuring perceptions of control or influence at the three levels of analysis, to test the reliabilities of these indices, and to examine the correlates of perceptions of control using other questions included in the survey. We were also interested in the development of a 
single scale incorporating the three indices above, which could be used as a measure of a multilevel concept of empowerment: the combination of individual, organizational and community levels of control.

The twelve scale items followed a series of interview questions about involvement in voluntary organizations. These included national organizations, neighborhood organizations, churches, and a variety of other voluntary membership organizations. Participants were asked to consider all of the organizations of which they were members, and to select the one organization which was most important to them. The questions measuring perceived control at the organizational level were asked with respect to that organization. Respondents who were not members of any organizations were not asked these questions. A four-point response scale, ranging from 1 = disagree strongly to $4=$ agree strongly, was used for all the items. The twelve items measuring perceived influence are shown in Appendix A, along with items in the other major scales described below.

A factor analysis of the 12 scale items resulted in three factors which correspond to perceived control at the individual, organizational and community levels. (See Appendix A for a description of the scales and scale items). Cronbach alphas for the three subscales were .66 for the individual level (two items), .61 for the organizational level (five items), and .63 for the community level (four items). The Cronbach alpha for a multilevel scale including all 12 items was .71. Because the organizational questions were only asked of those individuals who reported membership in at least one organization, the scales which include these measures (multilevel and organizational scales) include only individuals who were members of one or more organization: those who were not members of organizations were dropped from the analysis. The individual and community scales include both individuals who are members of groups and those who reported no group memberships. Correlations among the three subscales are: .15 between individual 
and organizational; .22 between individual and community; and .39 between organizational and community. The multilevel scale is highly correlated with the individual, organizational and community scales of which they are comprised.

Demographic variables. Self reported race of respondent ( $1=$ black, $2=$ white), gender $(i=$ female, $5=$ male), age, income ( 23 categories ranging from $1=$ less than $\$ 2,999$ to $23=\$ 90,000$ or more) and education (eight categories ranging from $1=0-4$ years and $8=$ graduate degree) were collected as part of the survey.

Perceived effectiveness of action (effectiveness). The perceived effectiveness scale was created to assess respondent perceptions of the effectiveness of taking a variety of actions to influence community issues. It is the sum of responses to seven items (see Appendix A) which assessed the perceived effectiveness of a variety of actions an individual might take to influence community issues (for example: working for a political candidate or writing letters to a public official). The Cronbach alpha for this scale was .79. The mean for this scale was 23.2, with a standard deviation of 3.7.

Action to influence community issues (action). An action scale was constructed from 12 items (see Appendix A) which measured actions taken by the study participant to influence community issues during the 12 months prior to the survey (for example: worked for a political candidate during the past 12 months, or wrote letters to a public official during the last 12 months). The Cronbach alpha for this scale was .80 . The mean for this scale was 20.3 , with a standard deviation of 9.8 .

Organizations attempt to influence public policy (influence). The influence scale was created by summing participants' responses to questions assessing the extent to which each group of which they were a member attempted to influence public policy ( $1=$ rarely or never, 2 =sometimes or often), then dividing the total by the number of groups for which they reported membership. Data for this variable include only 
respondents who reported memberships in one or more groups. The mean for the scale was 2.8 with a standard deviation of $($ Mean $=2.8 ;$ s.d. $=1.1)$

Extent of participation in voluntary organizations (participation). The participation scale was designed to provide a measure of the extent of involvement an individual respondent reported in groups in which they were members. This scale was created by summing the responses to questions (Appendix A) about level of activity (not very $=1$, somewhat $=2$, very $=3$ ) and leadership role within the last 12 months (no $=1$, yes $=2$ ) for organizations in which the respondent was a member $($ alpha $=.79)$. This scale includes only participants who reported membership in one or more groups. $($ Mean $=4.3 ;$ s.d. $=1.2)$

Analysis procedures

Comparisons were made between group members and non-members with respect to age, race, gender, income, education, perceived control, perceived efficacy of action, and actions taken in the past 12 months. These tests were followed by analyses of co-variance (ANCOVA) to test whether the relationship of group participation to the perceived control indices remained significant when controlling for important demographic variables. Finally, a series of stepwise regression analyses were conducted to examine the correlates of the individual, organizational, community and global scales. Only study participants who were members of one or more groups were included in these analyses. The perceived control scales were the dependent variables, with demographic variables and the perceived effectiveness of action, actions taken to influence community issues, membership in organizations which attempt to influence public policy, and extent of participation in voluntary organizations as independent variables. Table 1 reports the zero-order correlations among the independent variables.

Table 1 Here 


\section{Results: Effects of Participation in Voluntary Organizations and Correlates of Perceived Control at Multiple Levels}

\section{Comparison of organization members and non-members}

Tests of difference between respondents who were members of organizations $(n=291)$ and those who reported no organization memberships $(n=616)$ are reported in Table 2. Chi-square results show that organizational members did not differ significantly from non-members with respect to race $\left(X^{2}=1.4\right.$, d.f. $\left.=1, n . s\right)$ or gender $\left(X^{2}=0.0\right.$, d.f. $\left.=1, n . s\right)$. Organizational members were older than non-group members $(F=4.1$; d.f. $=1 ; p<.001)$, and had more education $(F=-7.6$; d.f. $=$ $1 ; \mathrm{p}<.001)$ and higher incomes $(\mathrm{F}=-6.5 ;$ d.f. $=1 ; \mathrm{p}<.001)$.

A comparison of members of voluntary organizations with non-members with respect to the perceived control, action and effectiveness scales showed significant differences. Members of organizations were more likely than non-members to "believe that taking action was effective and were more likely to have taken action in the 12 months prior to the survey. Members were more likely to believe that they had influence over both their personal lives and community events, as illustrated by differences in the individual and community perceived control scales respectively.

Table 2 Here

Because participation in voluntary organizations was associated with both the demographic variables (age, income and education) and the perceived control variables, an ANCOVA was conducted to test whether an independent relationship existed between group participation and perceived control when controlling for the demographic variables. The results of this analysis are shown in Table 3 and indicate that participation in voluntary organizations is uniquely and significantly related to levels of perceived control. Moreover, the relationship of group 
membership with the perceived effectiveness of taking action and having taken action in the past twelve months is significant.

\section{Table 3 Here}

\section{Correlates of perceived control among members of voluntary organizations}

To explore the correlates of perceived control among members of voluntary organizations, a series of stepwise multiple regression analyses were conducted, including only those respondents who reported membership in one or more organization. The dependent variables were: 1) the 12-item multilevel control scale; 2) individual control; 3) organizational control; and 4) community control. The independent variables were added to the analysis in the following order: 1) demographic variables (gender, income, education, race and age); 2) effectiveness scale; 3) action scale; 4) influence scale; and 5) participation scale. Tables 4 through 7 present the results of these regressions for each dependent variable. The standardized beta coefficients for each variable are reported in these tables, along with the total amount of variance $\left(R^{2}\right)$ that is explained by all variables at each step, the change in $\mathrm{R}^{2}$ that represents the contribution of the variable or block of variables added in that step, and the significance of the change in $R^{2}$.

Perceived control at multiple levels. The data presented in Table 4 shows that each of the steps in the stepwise regression analysis explains a significant amount of the variance $(p<.01)$ of perceived control at multiple levels, and that the full model (step 5) explains $23 \%$ of the variance. The change in $\mathrm{R}^{2}$ indicates that the contribution of each variable or block of variables makes a significant contribution $(p<.01)$ to explained variance over and above that provided in the blocks of the previous step. Participation in groups which attempt to influence public policy, activity level and leadership roles in organizations, and the perceived effectiveness of taking action account for large amounts of the explained variance. 
An examination of the beta coefficients across the steps helps us to understand the effects of individual variables within the blocks and also the extent to which the variables in each of the steps are affected as new variables are entered. The effects of race and education are reduced by the action, influence and participation variables (the race and education coefficients decline from -.14 and .15 respectively in step 2 to -.03 and .09 respectively in step 5 . The effect of the action index declines as the group influence variable enters the model and is further reduced by the addition of the participation variable to the model.

Table 4 Here

\section{Perceived control at the individual level}

Table 5 presents the results of the stepwise regression analysis with perceived control at the individual level as the dependent variable. In this case, the $\mathrm{R}^{2}$ data shows that only the first step in the regression analysis is significant $(\mathrm{p}<.05)$, and explains only $3 \%$ of the total variance in the individual perceived control scale. The full model does little to explain the additional variance in the scale. In the first steps of the analysis race and gender are significant and account for the greatest amount of variance, with women and black respondents reporting lower rates of perceived control. As additional items are included in the model, the effects of race and gender become insignificant.

\section{Table 5 Here}

\section{Perceived control at the organizational level}

As indicated by the $\mathrm{R}^{2}$ data reported in Table 5, each of the blocks in the stepwise regression analysis is a highly significant predictor of perceived control at the organizational level $(p<.01)$. The full model explains $26 \%$ of the total variance, 
and the change in $\mathbf{R}^{2}$ statistic shows that the addition of each block of variables makes a significant unique contribution in explained variance.

The effect of race is reduced when the influence and the participation variables are entered into the equation. The beta coefficient drops from .22 in step 2 to .10 in step 5 . The effects of education are reduced by these two variables, dropping from .16 in step 2 to .10 in step 5. Finally, the action index is not significant when the influence and participation variables are entered into the equation. The final two steps account for $12 \%$ of the variance in the perceived organizational control scale.

Table 6 Here

Perceived control at the community level

Each of the first four steps in the regression analysis presented in Table 7 explains a significant amount of the variance in perceived community control, and the full model explains $14 \%$ of the total variance. Age has a significant effect at each step of the analysis: it does not appear to be affected by the addition of the action, influence and participation variables. In this model, the perceived effectiveness of taking action and participation in organizations which attempt to influence public policy account for the largest increments of explained variance. The participation variable, which measures the level of activity and leadership roles in organizations does not add to the explanatory value of the model. A relatively strong initial effect of action is reduced by the addition of the variable measuring participation in organizations which attempt to influence public policy.

Table 7 Here 


\section{Discussion}

\section{Overview of results}

The first question we examined was whether there were significant differences between individuals who were members of voluntary organizations and those who were not on measures of individual and community control, perceived effectiveness of action, and likelihood of taking action. The results suggest that participants in voluntary organizations were older, better off financially, and had more education than individuals who were not members of voluntary organizations. In turn, organizational members reported higher levels of perceived control at the individual and community levels, were more likely to say that actions are effective means to influence community issues, and were more likely to have taken some action to influence community issues within the past 12 months. These differences continued to be significant when demographic variables were controlled. These results are consistent with others who found participation to be associated with personal control (Kieffer, 1984; Florin and Wandersman, 1984; Zimmerman and Rappaport, 1988).

Our second question explored predictors of perceived control among individuals who were members of voluntary organizations, based on the conceptual model outlined in this article. We examined these predictors using a multi-level scale measuring perceived control at the individual, organizational and community level as a dependent variable, and also disaggregated this scale into three separate scales representing the different levels of analysis.

The conceptual model did not fit the individual level of perceived control scale very well. Only race and gender predicted individual control, and this reached significance only in the first steps of the analysis. This lack of fit between the model and this dependent variable may be a limitation of the scale, the model, or both.

The scale included assessments of perceived control over life events and satisfaction 
with that control: these items may not be linearly related. The predictors used in the model focus on attempts to influence community events. The relationship between perceived control at the individual level and beliefs and actions related to community control may be more complex than allowed for in this model. For example, motivation to control, or perceived efficacy in a specific setting, may prove to be important predictors of perceived control at the individual level.

Among respondents who were members of one or more groups, perceived effectiveness of taking action to influence community issues, and participation in groups which attempt to influence public policy were consistently important in explaining the variance in perceived control at the organizational and community levels. The extent of leadership and activity in voluntary organizations was also strongly associated with the organizational and multi-level scales, but not with perceived control at the community level.

The model used in these analyses was most effective in explaining variance at the organizational level. Research in the area of stress and control has suggested that perceived personal control may be domain specific - that individuals may feel influential in one arena but not in others (Israel and Schurman, 1990). The questions which comprise the organizational control scale were specific to an. organization selected by the respondent, while the questions which referred to perceived control at the individual and community level were more general. This may account for the greater specificity of the model at the organizational level. Scale items which provide more domain-specific measures of control at the individual and community levels may provide greater explanatory value.

Overall, the analysis of the three component scales which comprise the multilevel index is informative. It suggests that the most important factors linked with perceived control at the organizational level are participation in groups which attempt to influence public policy, and the level of participation or engagement in 
organizations (activity level and taking a leadership position). The perceived effectiveness of taking action is also important at this level. At the community level, participation in groups which attempt to influence public policy is again important, as is the effectiveness scale. The appearance of the influence variable and the effectiveness variable as important at both levels supports a relationship between perceived control at the organizational and community levels, as suggested by the conceptual model which informed this analysis. These findings are consistent with prior research which has linked action and the ability to influence personal and community events as important aspects of empowerment (Kieffer, 1984; Wandersman, 1985; Zimmerman, 1991).

The conceptual model fits the multi-level perceived control scale reasonably well, accounting for $23 \%$ of the variance in the model. When disaggregated into its component parts, the amount of variance accounted for at each of the levels of analysis varied from $5 \%$ to $26 \%$. In addition, different variables were significant predictors of perceived control at the different levels of analysis.

\section{Limitations}

The scales used in these analyses provide a partial measure of empowerment, examining individual perceptions of control at multiple levels. These perceptions were assessed by use of a survey instrument with closed ended items, which limits the ability to capture the complexity and richness of the empowerment concept. While perceptions of control are likely to be to some extent a function of actual experience, and are likely to be related to individual attempts to exert influence or control over community events, they remain individual perceptions. The scale does not provide an objective measure of control, nor does it provide a collective assessment, at the level of the organization or the community, of perceived or actual control. In-depth semi-structured interviews, focus groups, and community observations may be necessary to more completely capture the concept of 
empowerment at multiple levels of analysis. The scales as we have constructed and tested them provide only a snapshot of perceived control at one point in time. They do not illuminate the interactions among the different components, the direction of cause and effect, or changes in levels of perceived control over time as they relate to changes in the social environment. Analyses using qualitative methods conducted in conjunction with the use of the model and repeated measures with the scale over time would help to clarify the dialogic process of perceived control as a component of empowerment, and might help to explore the relationships among perceived control at the individual, organizational, and community levels.

The term 'community' was not explicitly defined in the questionnaire, leaving participants to respond to questions based on their own definitions. We do not know what definitions respondents used (e.g. urban block, a city, "the Black community"), in responding to the scale items, and differences in meanings may influence the interpretations of the results. Further exploration and specification of individual and group conceptions of community would further the exploration of empowerment at the community level, and might help to develop more domainspecific assessments of empowerment.

The development of critical consciousness, which has been identified as a key aspect of the empowerment process, is not measured directly by any of the measures we used in this study. Some of the independent variables we used may provide an indirect measure of the components of critical consciousness. For example, individuals who are very active in voluntary organizations may be more likely to have a sense of identification with similar others in that group; involvement in organizations which attempt to influence public policy may reflect a sense of responsibility for future personal and social conditions; and the dialectical process of action and reflection which has been identified as key to the development of critical consciousness may be more likely to occur among individuals who are 
engaged in organizations attempting to influence public policy. More direct measures of critical consciousness would be helpful, as would assessment over time to explore the development of a critical consciousness with respect organizational and community involvement, action and reflection.

Finally, the study was based on survey respondents from a large urban area in the Midwest, and the analysis was limited to respondents of either AfricanAmerican or European-American descent, due to the small numbers of respondent from other racial/ethnic groups. The concepts of community, control and power or empowerment may vary across cultural groups as well as across regions. The importance of organizational involvement in this analysis may also reflect an urban or industrial bias. Rural or kinship based communities, or different cultural groups, may emphasize different components or factors as important to empowerment or empowering processes. Notably absent from the model discussed here is a spiritual component of empowerment, noted by some authors (Haniff, 1989). Further testing with different groups would be useful to assess the applicability of this model in different settings and with different populations.

\section{Implications for Practice}

The analyses reported here support prior work which links organizational participation with increases in perceived individual and community control. In addition, they suggest that individuals who are members of voluntary organizations are more likely than those who are not members to believe that actions can be taken to influence community issues, and are more likely to have taken some action in the past year. While the direction of these effects can not be determined from this study, it seems logical that there is a reciprocal effect, with a minimum level of belief in the effectiveness of action necessary for an individual to act, and feedback on the effectiveness of that action in turn influencing perceived control. This suggests that real participation and influence in community and organizational 
decision making can influence individual perceptions of control as one component of empowerment.

Interventions designed to maximize the opportunities for active participation in different tasks within organizations can help individuals develop skills and influence processes within the organization as well as in the community, and thus enhance perceptions of control. Opportunities for leadership development within the organization may also be an important aspect of the development of a sense of and ultimately the empowerment of organizational members. And finally, interventions which encourage voluntary organizations to take an active role in community and public policy issues may facilitate the empowerment of individuals who participate in these organizations. Practitioners who create opportunities for such participation can enhance the empowering effects of their interventions.

\section{Conclusion}

This study's development of a measure of perceived control at multiple levels as one aspect of empowerment has both lessons and limitations. The findings reported here support the use of a multilevel conceptualization of empowerment. The indices examined provide further evidence that there are separate, distinct levels of control that can be combined to capture a broader, multilevel construct. The results of this study move us toward a measurement of empowerment and its correlates and toward a more complete understanding of the dynamics of this complex process.

These findings suggest the importance of participation in voluntary organizations as an aspect of perceived control at the individual and community levels. Furthermore, among those individuals who are members of voluntary organizations, active involvement or leadership activities in organizations which attempt to influence public policies are correlated with perceived organizational and community control. Interventions designed to encourage participation in voluntary 
organizations, provide opportunities for members' active participation and leadership development within those organizations, and facilitate the efforts of voluntary organizations to act on community and public policy issues may enhance perceived control at the individual, organizational and community levels. 


\section{References}

Alinsky, Saul (1972). Rules for Radicals. New York: Random House.

Bandura, Albert (1982). Self-efficacy mechanism in human agency. American Psychologist 37:122-147.

Bookman, Ann and Morgen, Sandra. (1988). Women and the Politics of Empowerment. Philadelphia: Temple University Press.

Checkoway, Barry N. and Norseman, A. (1986). Empowering citizens with disabilities. Community Development Journal 21:270-277.

Chesler, Mark and Chesney, Barbara. (1989). Self-Help Groups: Empowerment Attitudes and Behaviors of Disabled or Chronically Ill Persons. In Harold E. Yuker, (Ed.) Attitudes Toward Persons With Disabilities. New York: Springer Publishing Co.

Collins, Patricia Hill. (1990). Black Feminist Thought: Knowledge, Consciousness and the Politics of Empowerment. Boston: Unwin Hyman, Inc.

Crowfoot, James. (1981). Accommodating growth in democratically managed organizations. Moving Food: A Trade Journal of the Cooperating Food Distribution System, March-April:40-43.

Cottrell, Leonard Jr. (1976). The competent community. In Berton Kaplan, Robert Wilson and Alexander Leighton, (Eds.) Further Explorations in Social Psychiatry. New York: Basic Books.

Florin, Paul and Wandersman, Abraham. (1980). An introduction to citizen participation, voluntary organizations and community development: Insights for empowerment through research. American Journal of Community Psychology, 18(1):41-54. 
Florin, Paul and Wandersman, Abraham. (1984). Cognitive social learning and participation in community development. American Journal of Community Psychology, 12:689-708.

Freire, Paulo. (1970). Pedagogy of the Oppressed. New York: Seabury Press. Freire, Paulo. (1973). Education for Critical Consciousness. New York: Seabury Press.

Garvin, C. (1985). Work with disadvantaged and oppressed groups. In Martin Sundel, P. Glaser, R. Sarri and R. Vinter (Eds.) Individual Change Through Small Groups, 2nd edition. New York: The Free Press.

Gerschick, Thomas J., Israel, Barbara A. and Checkoway, Barry. (1990). Means of Empowerment in Individuals, Organizations and Communities: Report on a Retrieval Conference, May 8-9, 1989. Program in Conflict Management Alternatives, CRSO, University of Michigan, Ann Arbor, Michigan.

Gibson, James, L. Ivanavich, John M. and Donnelly, James, Jr. (1973).

Organizations: Behavior, Structure, Processes. Dallas: Business Publications, Inc.

Gutierrez, Lorraine. (1988a). Working with Women of Color: An empowerment perspective. Paper presented at the Annual Conference of the National Association for Social Workers "Choices and Challenges" Philadelphia, PA. Gutierrez, Lorraine. (1988b). Copirg with stressful life events: An empowerment perspective. Working Paper, University of Michigan School of Social Work, Ann Arbor, MI, 48109.

Gutierrez, Lorraine. (1989). Ethnic consciousness, consciousness raising and the empowerment process of Latinos. Unpublished doctoral dissertation. University of Michigan School of Social Work, Ann Arbor, MI. Haniff, Nesha. (1989). Blaze a Fire. Toronto: Sister Vision: Black Women of Color Press. 
Israel, Barbara A. and Schurman, Susan J. (1990). Social support, control and the stress process. In K. Glanz, F. Lewis and B. Rimer (Eds.) Health Behavior and Health Education: Theory, Research and Practice. San Francisco:Jossey-Bass.

Israel, Barbara A., Checkoway, Barry, Schulz, Amy and Zimmerman, Marc. (1992). Multiple levels of empowerment: Perceptions of individual, organizational and community control. Under review.

Israel, Barbara A., House, James S., Schurman, Susan J., Heaney, Catherine A. and Mero, Richard P. (1989). The relation of personal resources, participation, influence, interpersonal relationships and coping strategies to occupational stress, job strains and health: A multivariate analysis. Work and Stress, 3(2):163-194.

Israel, Barbara A., Schurman, Susan J. and House, James S. (1989). Action research on occupational stress: Involving workers as researchers. International Journal of Health Services, 19(1): 135-155.

Kasl, Stan and Cooper, Cary. (1987). Stress and Health; Issues in Research Methodology. New York: John Wiley and Sons.

Keefe, T. (1980). Empathy, skill and critical consciousness. Social Casework, 61:387-393.

Kieffer, Charles (1984). Citizen Empowerment: A Developmental Perspective. Prevention in Health Services, 3(2/3):9-36.

Maier, S. and Seligman, Martin. (1976). Learned helplessness: Theory and evidence. Journal of Experimental Psychology: General, 105(1):3-46.

Pinderhughes, Elaine. (1985). Power, powerlessness and practice. In Sylvia Gray, Ann Hartmann and E. Saalberg (Eds) Empowering the Black family: A Roundtable Discussion. National Child Welfare Training Center, Ann Arbor, MI. 
Rappaport, Julian. (1987). Terms of empowerment/examples of prevention:

Toward a theory for community psychology. American Journal of Community Psychology, 15(2):121-148.

Rappaport, Julian. (1985). The power of empowerment language. Social Policy, 17 (2): $15-21$.

Rappaport, Julian. (1981). In praise of paradox: A social policy of empowerment over prevention. American Journal of Community Psychology, 9(1):1-25.

Russell, C. and Sarri, Rosemary. (1984). Mutual aid and self help groups: A review of the literature with implications for research and service delivery. Unpublished manuscript. University of Michigan, School of Social Work. Ann Arbor, MI.

Sarri, Rosemary and DuRivage, V. (1985). Strategies for self help and empowerment of working low income women who are heads of families. Unpublished manuscript. University of Michigan, School of Social Work. Ann Arbor, MI

Schulz, Amy and Israel, Barbara A. (1990). Empowerment and Empowering Processes: A Theory Development Seminar Series. PCMA Working Paper \# 27, University of Michigan, Ann Arbor, MI.

Schultz, R. (1980). Aging and control. Human Helplessness: Theory and Applications, Judy Garber and Martin Seligman, (Eds.). New York: Academic Press.

Solomon, Barbara. (1970). Black Empowerment. New York: Columbia University Press.

Stensrud, Robert and Stensrud, Kay. (1982). Counseling for health empowerment. Personnel and Guidance Journal, 60(6):377-381.

Syme, S. Leonard. (1986). Strategies for health promotion. Preventive Medicine, 15:492-507. 
Wallerstein, Nina (1992). Powerlessness, empowerment, and health: Implications for health promotion programs. American Journal of Health Promotion, 6(3):197-205.

Wandersman, Abraham, Florin, Paul, and Chavis, David. (1985). Getting together and getting things done. Psychology Today, 19:64-65.

Withorn, A. (1980). Helping ourselves: The limits and potentialities of self help. Social Policy, 11(3):20-28.

Zimmerman, Marc A. (1986). Citizen empowerment, perceived control and psychological empowerment. Paper presented at the meeting of the American Psychological Association, Washington D.C.

Zimmerman, Marc A. (1990). Taking aim on empowerment research: On the distinction between individual and psychological conceptions. American Journal of Community Psychology, 18(1):169-17.

Zimmerman, Marc A. (1990). Toward a theory of learned hopefulness: A structural model analysis of participation and empowerment. Journal of Research and Personality, 1:71-86.

Zimmerman, Marc A. and Rappaport, Julian. (1988). Citizen participation, perceived control and psychological empowerment. American Journal of Community Psychology, 16(5):725-750.

Zimmerman, Marc A. and Zahniser, James H. (1991). Refinements of spherespecific measures of perceived control: Development of a sociopolitical control scale. Journal of Community Psychology, 19(2):189-209. 
Figure 1: Correlates of Multiple Levels of Perceived Control as an Aspect of Empowerment*

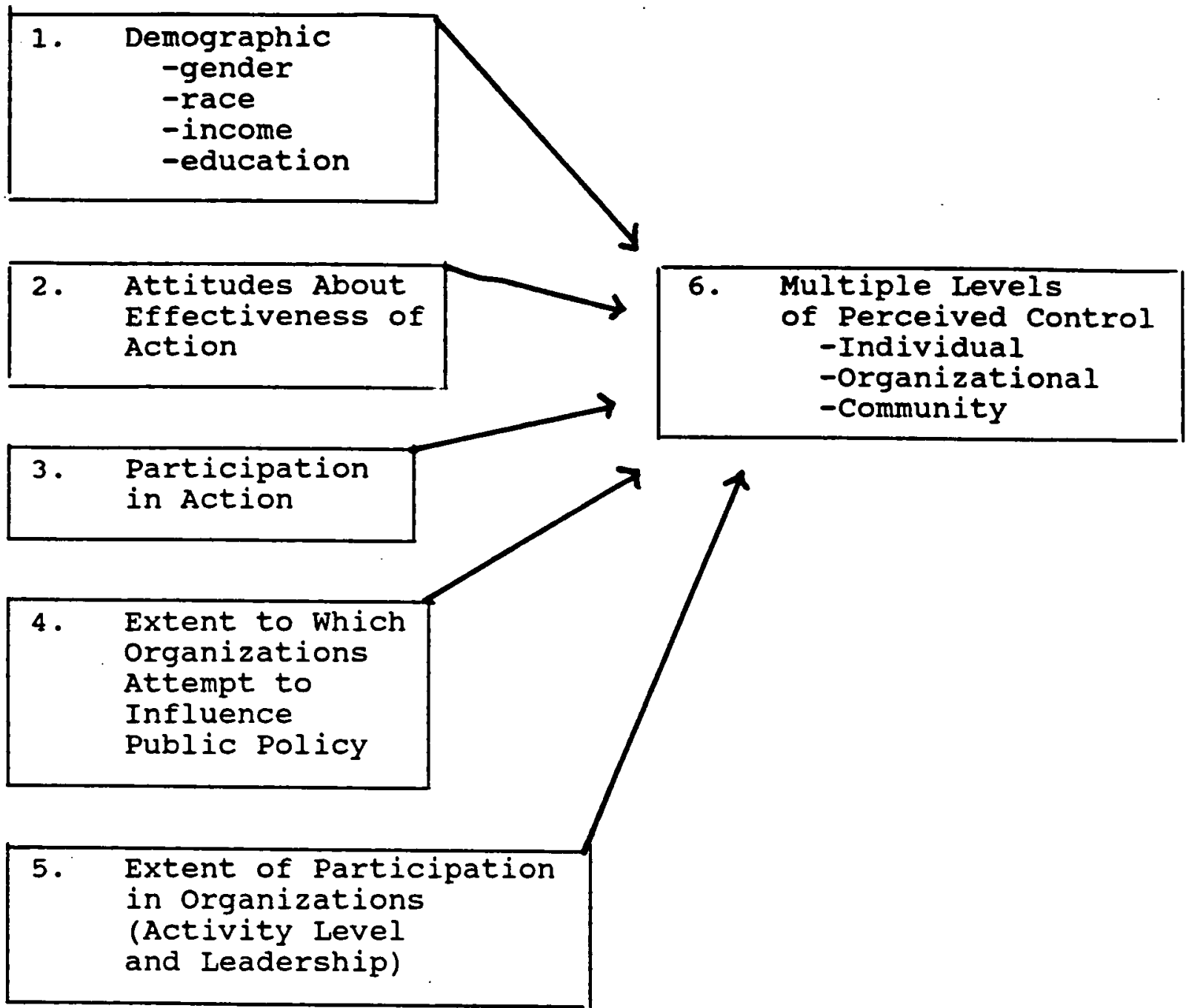

* Numbers refer to the step in the regression analysis and reflect the impact of the addition of that variable over and above the impact of the variable entered in the prior step. 
Table 1

Zero order Correlations of Predictor Variables

\begin{tabular}{lllllllll}
1 & 2 & 3 & 4 & 5 & 6 & 7 & 8 & 9 \\
\hline
\end{tabular}

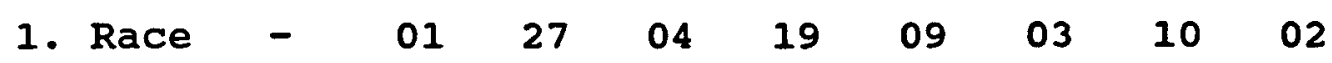

2. Gender - $\begin{array}{llllllll}15 & 03 & 03 & 04 & 06 & 01 & 03\end{array}$

$\begin{array}{llllllll}3 . & - & 06 & 47 & 06 & 26 & 16 & 17\end{array}$

$\begin{array}{lllllll}\text { 4. Age } & - & 31 & 05 & 01 & 09 & 14\end{array}$

5. Education $\quad-\quad \begin{array}{lllll}05 & 35 & 24 & 19\end{array}$

6. Effectiveness - $21 \quad 16 \quad 13$

7. Action - $\quad 39 \quad 37$

8. Influence - 63

9. Participation - 
Table 2: Differences Between Group Members and Non-Memberse

\begin{tabular}{|c|c|c|c|}
\hline \multirow[t]{2}{*}{ Variable } & \multicolumn{2}{|c|}{ Mean } & $t$ value/s \\
\hline & Group Member & Non-Member & \\
\hline $\begin{array}{l}\text { Age } \\
\text { Education } \\
\text { Income } \\
\text { Individual }\end{array}$ & $\begin{array}{r}45.6 \\
5.4 \\
12.7\end{array}$ & $\begin{array}{r}40.5 \\
14.7 \\
9.5\end{array}$ & $\begin{array}{l}-4.1 * \star * \\
-7.6 * \star \star \\
-6.5 * \star *\end{array}$ \\
\hline $\begin{array}{l}\text { control } \\
\text { Community }\end{array}$ & 6.6 & 6.3 & $-3.1 * *$ \\
\hline $\begin{array}{l}\text { control } \\
\text { Effectiveness } \\
\text { Action }\end{array}$ & $\begin{array}{l}13.7 \\
23.6 \\
20.2 \\
\end{array}$ & $\begin{array}{l}12.6 \\
22.3 \\
13.3 \\
\end{array}$ & $\begin{array}{l}-5.9 * \star \star \\
-3.9 * * \star \\
-11.2 * \star *\end{array}$ \\
\hline
\end{tabular}

$\begin{array}{ll}\star & p<.05 \\ \star \star & p<.01 \\ \star \star \star & p<.001\end{array}$

a Tests were not conducted for the multi-level and organizational level of perceived control because these analyses can only be carried out with members of organizations 
Table 3:Effects of Group Participation on Perceived Control, Controlling for Age, Education and Income

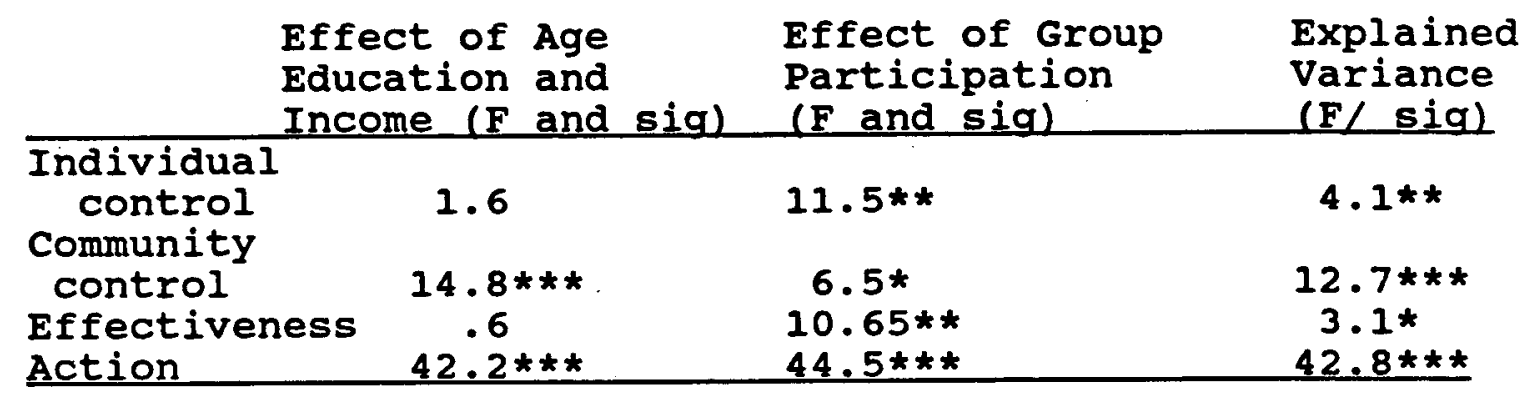

$\begin{array}{ll}\star & \mathrm{p}<.05 \\ \star \star & \mathrm{p}<.01 \\ \star \star \star & \mathrm{p}<.001\end{array}$

a Tests were not conducted for the multi-level and organizational level of perceived control because these analyses can only be carried out with members of organizations. 
Table 4: Beta Coefficients and Significance for Five step Regression Analysis With Perceived Control at Multiple Levels (12 item scale) e

\begin{tabular}{|c|c|c|c|c|c|}
\hline \\
\hline & 1 & 2 & 3 & 4 & 5 \\
\hline $\begin{array}{l}\text { Gender } \\
\text { Age } \\
\text { Race } \\
\text { Income } \\
\text { Education } \\
\text { Effectivene } \\
\text { Action } \\
\text { Influence } \\
\text { Participati }\end{array}$ & $\begin{array}{l}-.11 * \\
.17 \star \star \star \\
-.17 \star \star \star \\
-.00 \\
.15 * \star \\
\text { ess } \\
\text { ion } \\
\end{array}$ & $\begin{array}{l}-.09 \\
.18 \star \star \star \\
-.14 * \star \\
-.03 \\
.15 * \star \\
.21 * \star \star\end{array}$ & $\begin{array}{l}-.10 * \\
.17 * * \star \\
-.13 * * \\
-.04 \\
.10 \\
.18 * * * \\
.14 * *\end{array}$ & $\begin{array}{l}-.10 * \\
.17 \star \star \star \\
-.04 \\
-.03 \\
.08 \\
.17 \star \star \star \\
.10 \star \\
.26 \star \star \star\end{array}$ & $\begin{array}{l}-.09 * \\
.15 * \star \\
-.03 \\
-.04 \\
.09 \\
.16 * \star \star \\
.07 \\
.26 * \star \star \\
.21 * \star \star\end{array}$ \\
\hline $\begin{array}{l}\text { Total } \mathrm{R}^{2} \\
\text { Change } \mathrm{R}^{2} \\
\text { Change } \mathrm{F}\end{array}$ & $\begin{array}{c}.07 \\
.07 \\
6.2 \star \star \star\end{array}$ & $\begin{array}{c}.11 \\
.04 \\
19.8 * \star \star\end{array}$ & $\begin{array}{c}.13 \\
.02 \\
8.0 * \star\end{array}$ & $\begin{array}{c}.19 \\
.06 \\
30.5 * \star \star\end{array}$ & $\begin{array}{c}.23 \\
.04 \\
22.4 \star \star \star\end{array}$ \\
\hline
\end{tabular}

\footnotetext{
* $\quad \mathrm{p}<.05$

$\star * \quad p<.01$

$\star \star * \mathrm{p}<.001$
}

eThis analysis includes only those respondents who reported membership in one or more voluntary organization. 
Table 5: Beta Coefficients and Significance for Five Step Regression Analysis with Perceived Control at the Individual Level (2-item scale) e

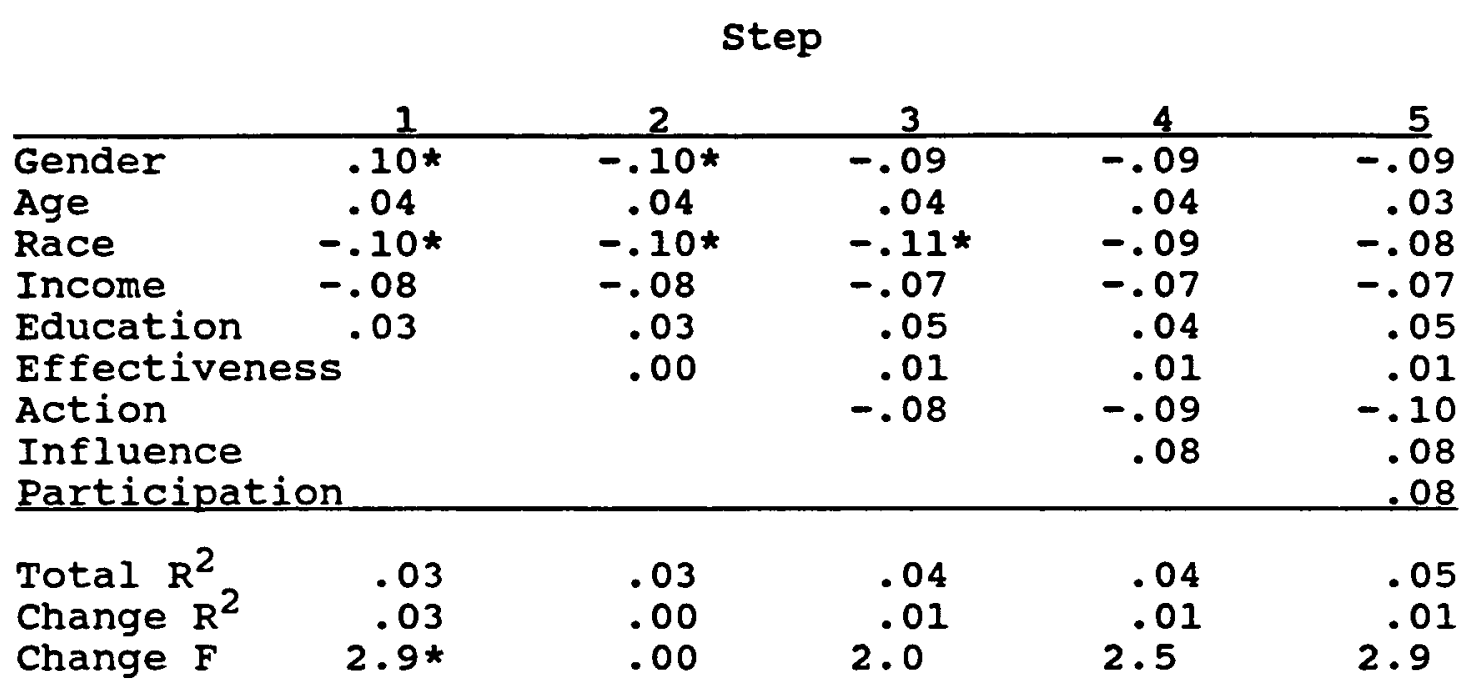

\footnotetext{
* $\mathrm{p}<.05$

$\star \star \quad \mathrm{p}<.01$

$\star * * p<.001$
}

eThis analysis includes only those respondents who reported membership in one or more voluntary organization. 
Table 6:Beta Coefficients and Significance for Five Step Regression Analysis With Perceived Control at the organizational Level (5-item scale) $\mathrm{e}$

\section{Step}

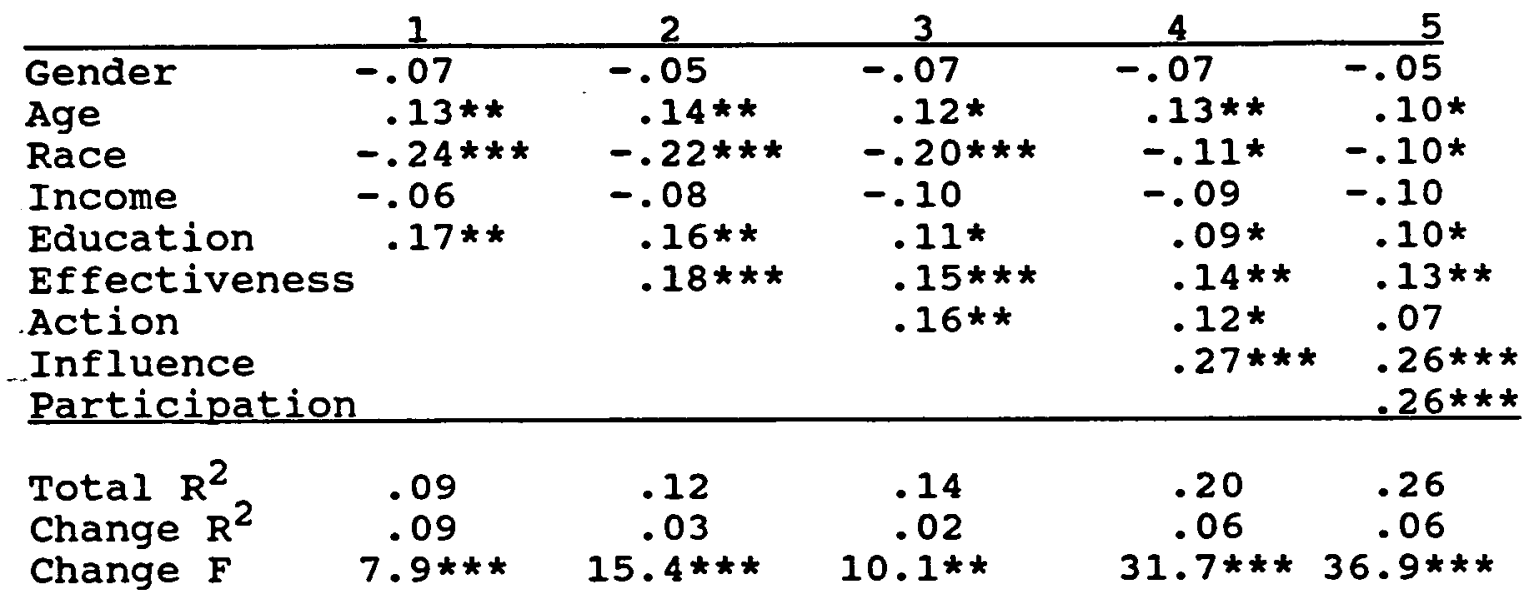

\footnotetext{
* $\quad \mathrm{p}<.05$

$\star * \quad \mathrm{p}<.01$

$\star * * \mathrm{p}<.001$
}

eThis analysis includes only those respondents who reported membership in one or more voluntary organization. 
Table 7: Beta Coefficients and Significance for Five step Regression Analysis with Perceived Control at the Community Level (4-item scale) e

\begin{tabular}{|c|c|c|c|c|c|}
\hline \multicolumn{6}{|c|}{ step } \\
\hline $\begin{array}{l}\text { Gender } \\
\text { Age } \\
\text { Race } \\
\text { Income } \\
\text { Education } \\
\text { Effectiveness } \\
\text { Action } \\
\text { Influence } \\
\text { Participation }\end{array}$ & $\begin{array}{l}1 \\
-.08 \\
.17 * * * \\
-.01 \\
.12 \\
.10 \\
\end{array}$ & $\begin{array}{l}2 \\
-.06 \\
.17 \star \star \star \\
.02 \\
.08 \\
.09 \\
.21 \star \star \star\end{array}$ & $\begin{array}{l}3 \\
-.08 \\
.16 * \star \\
.04 \\
.06 \\
.05 \\
.18 * \star \star \\
.15 * \star\end{array}$ & $\begin{array}{l}4 \\
-.08 \\
.17 * \star \star \\
.09 \\
.07 \\
.03 \\
.17 \star \star \star \\
.12 \star \\
.18 \star \star \star \\
\end{array}$ & $\begin{array}{l}5 \\
-.07 \\
.16 * \star \\
.10 \\
.07 \\
.03 \\
.17 * \star \star \\
.11 * \\
.18 * \star \star \\
.07\end{array}$ \\
\hline $\begin{array}{l}\text { Total } \mathrm{R}^{2} \\
\text { Change } \mathrm{R}^{2} \\
\text { Change } \mathrm{F}\end{array}$ & $\begin{array}{l}.05 \\
.05 \\
4.3 * \star \star\end{array}$ & $\begin{array}{c}.09 \\
.04 \\
19.0 * * *\end{array}$ & $\begin{array}{l}.11 \\
.02 \\
8.6 * \star\end{array}$ & $\begin{array}{l}.13 \\
.03 \\
12.9 * * *\end{array}$ & $\begin{array}{l}.14 \\
.01 \\
2.5\end{array}$ \\
\hline $\begin{array}{ll}\star & \mathrm{p}<.05 \\
\star * & \mathrm{p}<.01 \\
\star \star \star & \mathrm{p}<.001\end{array}$ & & & & & \\
\hline
\end{tabular}

eThis analysis includes only those respondents who reported membership in one or more voluntary organization. 
Appendix A

Scale Items

\section{Perceived control scale items}

Perceived control at the individual level (alpha $=.66)$ includes items 6 and 8 below. Mean $=6.5, \min =2.0, \max =8.0$. s.d. $=1.4$.

Perceived control at the organizational level $($ alpha $=.61)$ includes items 1 through 5 below. Mean $=15.2, \min =6.0, \max =20.0$, s.d. $=2.7$.

Perceived control at the community level (alpha $=.63$ ) includes items 7,9,10,11 and 12 below. Mean $=13.4, \min =6.0, \max =20.0$, s.d. $=2.5$.

Perceived control at multiple levels (alpha $=.71)$ includes all 12 of the items below. Mean $=35.9, \min =21, \max =48$, s.d. $=4.8$.

For the first five items, the interviewer asked the participants to "please answer the following questions thinking about the organization that you identified as most important to you. Do you agree strongly, agree somewhat, disagree somewhat, or disagree strongly?

1. I can influence the decisions that this organization makes.

2. This organization has influence over decisions that affect my life.

3. This organization is effective in achieving its goals.

4. This organization can influence decisions that affect the community. 
5. I am satisfied with the amount of influence I have over decisions that this organization makes.

The interviewer then commented that "I have been asking about your participation in specific organizations. I am also interested in how much influence you think you have in your life and in your community. I am going to read you a list of statements. For each one, please tell me how strongly you agree or disagree."

6. I have control over the decisions that affect my life.

7. My community has influence over decisions that affect my life.

8. I am satisfied with the amount of control I have over decisions that affect my life.

9. I can influence decisions that affect my community.

10. By working together, people in my community can influence decisions that affect the community.

11. People in my community work together to influence decisions on the state or national level.

12. I am satisfied with the amount of influence I have over decisions that affect my community.

Effectiveness scale (alpha $=.79)$ (This scale is the sum of responses to the constituent items) Mean $=23.2 \min =8.0 \max =32.0$, s.d. $=3.7$.

Response scale for all items was $1=$ not at all effective; 2 =not very effective; $3=$ somewhat effective; and $4=$ very effective) 
1. How effective would working for a political candidate be in convincing public officials and institutions to do something: very effective, somewhat effective, not very effective, or not at all effective?

2. How effective would it be to contribute money to a political party, a candidate, or a political party?

3. Write letters to public officials or other people of influence?

4. Speak to or go to see public officials or other people of influence?

5. How effective would it be to attend meetings about some community issue or problem?

6. Demonstrate or protest?

7. Complain to a business or corporation?

$\because \quad$ 8. Boycott a business or corporation?

Action scale (alpha $=.80)$ (this index is the sum of responses to the constituent questions). $\mathrm{Mean}=20.3 \mathrm{~min}=10.0 \max =50.0$ s.d. $=9.8$.

Response scale to all items was $1=$ no; $5=$ yes.

1. Before (current month) 1988, did you ever attend a public meeting, rally, or protest about some community problem?

2. Before (current month) 1988, did you ever speak to, write to, or go to see a public official or some other person of influence in the community to express your views about some community problem?

3. Before (current month) 1988, did you ever work with others in your community to try to do something about some community problem?

4. Did you speak to, write to, or go to see a public official or some other person of influence in your community to express your views about a community issue or problem? 
5. During the past 12 months did you attend any meetings concerned with some community issue or problem?

6. Did you discuss politics with your family or friends?

7. During the past $\mathbf{1 2}$ months did you work for a political party or candidate, or for a group or organization concerned with a community issue or problem?

8. During the past 12 months did you contribute money to a candidate, a political party, or to a group concerned with a community issue or problem? 9. During the past 12 months did you take part in a rally or protest about some community issue or problem?

10. Did you complain to a business or corporation about some community issue or problem?

11. During the past 12 months, did you take part in a boycott against a business or corporation because of some community issue or problem? 12. During the past 12 months did you do anything (else) either alone or with others in your community to try. to do something about a community issue or problem?

The following questions were asked for each group of which the participant was a member.

Participation. (This scale is the sum of the responses to the constituent items, for the group named as most important to the respondent). mean $=4.3$ $\min =2.0 \max =8.0$ s.d. $=2.4$.

1. In the past 12 months have you served on a committee, helped organize meetings, or served in a position of leadership in (the group)? (Response scale $1=$ no, 2 =yes) 
2. In the past 12 months have you been very active, somewhat active, or not very active in (the group)? (Response scale $1=$ not very, 2 =somewhat, $3=$ very active).

Influence (This score is the response score to the question with respect to the organization which is most important to the respondent). Mean $=2.6$ $\min =1.0 \max =4.0$ s.d. $=1.1$.

1. How often does (the group) try to influence public policy or the actions of influential individuals, businesses, or other groups or organizations: often, sometimes, rarely or never? (Response scale $1=$ never, $2=$ rarely, 3 =sometimes, $4=$ often). 